\title{
BEHAVIOUR OF RANDOMLY DISTRIBUTED FIBER-REINFORCED SOIL
}

\author{
K.M. Girija ${ }^{1}$ \\ ${ }^{1}$ Associate Professor, PDA College of Engg., Gulbarga
}

\begin{abstract}
This study presents the laboratory investigation of engineering behavior of discrete fiber-reinforced soil. Locally available C- $\emptyset$ soil $(S M)$ is used as medium and polypropylene fibers with a constant aspect ratio $(l / d)$ are used as reinforcement. Soil is compacted with Standard Proctor's maximum density with low percentage of reinforcement ( 0 to $0.7 \%$ by weight of dry soil). CBR tests, direct shear tests and unconfined compression tests were conducted on un-reinforced as well as reinforced soil samples to investigate the strength characteristics of fiber-reinforced soil. The test results reveals that the inclusion of fibers in soil increases the CBR value, Unconfined Compressive strength and Shear strength of soil. It is noticed that the optimum fiber content for achieving maximum strength is approximately $0.4 \%$ to $0.6 \%$ of the dry weight of the soil.
\end{abstract}

Keywords: CBR test, Fiber reinforcement, Direct shear test, unconfined test

\section{INTRODUCTION}

The use of fiber reinforcement has been suggested in recent years for various geotechnical applications. A fiber grid is one adaptation of this concept and consists of discrete, fibrillated polypropylene fibers. Upon mixing a predetermined amount of fiber grid with soil at particular moisture provides a mechanical means for reinforcement of the soil matrix. The mechanical interlock effect of the fibers provides increased tensile strength and cohesion to the soil matrix. Laboratory tests measured an increase in the ability of the reinforcement soil to resist shear strain an increase in the post- peak strength response: and an increase in modulus of the soil. This reinforcement mechanism has potential in construction of highways and slopes.

\section{TESTING PROGAMME}

In the present investigation an attempt was made to study the effects of adding polypropylene fibers on the strength characteristics of locally available $\mathrm{C}-\varnothing$ soil compacted to Standard Proctor maximum density. In order to quantify the increase in strength of soil due to addition of fibers, a series of CBR tests, direct shear tests and unconfined compression tests were conducted with unreinforced as well as reinforced soil. All tests were carried out in accordance with the procedures prescribed in Indian Standards. Three specimens were used for each type of test. The averaged results of triplicate specimens were used for analysis.

Soil classification of the local soil taken for the study was classified as SM as per IS classification. The properties of Polypropelene fibers were Young's modulus $=3 \mathrm{GPa}$, Tensile strength $120 \mathrm{MPa}$, Specific gravity= 0.91 and linear density =
30 denier $(1$ denier $=$ mass in grams per 9000 m length of fiber). The fiber was cut into small pieces of $15 \mathrm{~mm}$ (average) lengths. The aspect ratio $(\mathrm{l}=15 \mathrm{~mm}$ and $\mathrm{d}=0.2 \mathrm{~mm})$ is 75 .

\section{CBR TESTS}

Soaked and Un-soaked California Bearing Ratio tests were performed with unreinforced and reinforced soil samples. The percentage of fiber in reinforced soil varies from 0.1 to $1 \%$ by dry weight of the soil.

Table1: Shows the soaked CBR values with different fiber contents

\begin{tabular}{|c|c|c|}
\hline S.No & Fiber content (\%) & CBR value (\%) \\
\hline 1. & 0.0 & 2.37 \\
\hline 2. & 0.2 & 2.58 \\
\hline 3. & 0.3 & 2.70 \\
\hline 4. & 0.4 & 2.91 \\
\hline 5. & 0.5 & 3.45 \\
\hline 6. & 0.6 & 2.58 \\
\hline 7. & 0.7 & 1.96 \\
\hline
\end{tabular}

Table2: Shows the Un-soaked CBR values with different fiber contents.

\begin{tabular}{|c|c|c|}
\hline S.No & Fiber content (\%) & CBR value (\%) \\
\hline 1. & 0.0 & 11.67 \\
\hline 2. & 0.2 & 12.00 \\
\hline 3. & 0.3 & 12.12 \\
\hline 4. & 0.4 & 13.13 \\
\hline 5. & 0.5 & 14.59 \\
\hline 6. & 0.6 & 16.05 \\
\hline 7. & 0.7 & 13.21 \\
\hline
\end{tabular}


The optimum fiber content in soaked and un-soaked samples is observed to be $0.5 \%$ and $0.6 \%$ respectively. At optimum fiber content the maximum increase in CBR value are 1.45 times and 1.37 times compared to the unreinforced soil for soaked and un-soaked conditions respectively.

\section{DIRECT SHEAR TEST}

In direct shear tests, both unreinforced and reinforced specimens were tested at the shearing rate of $1.25 \mathrm{~mm}$ per minute in direct shear box. The fiber content in reinforced specimens varied from $0.1 \%$ to $0.7 \%$ by dry weight of the soil.

Table 3: Shows the variation of shear parameters for different percentage of fiber content.

\begin{tabular}{|c|c|c|c|}
\hline S No & $\begin{array}{c}\text { Percentage } \\
\text { of } \\
\text { Fiber }\end{array}$ & $\begin{array}{c}\text { Value of } \\
\text { cohesion } \\
\text { Intercept=C } \\
\mathrm{kg} / \mathrm{cm} 2\end{array}$ & $\begin{array}{c}\text { Angle of } \\
\text { Internal } \\
\text { Friction }=\varnothing 0\end{array}$ \\
\hline 1. & 0 & 0.45 & 32.5 \\
\hline 2. & 0.2 & 1.57 & 37.6 \\
\hline 3. & 0.3 & 1.76 & 46.8 \\
\hline 4. & 0.4 & 2.16 & 50.8 \\
\hline 5. & 0.5 & 1.72 & 52.4 \\
\hline 6. & 0.6 & 1.42 & 51.4 \\
\hline 7. & 0.7 & 1.21 & 50.1 \\
\hline
\end{tabular}

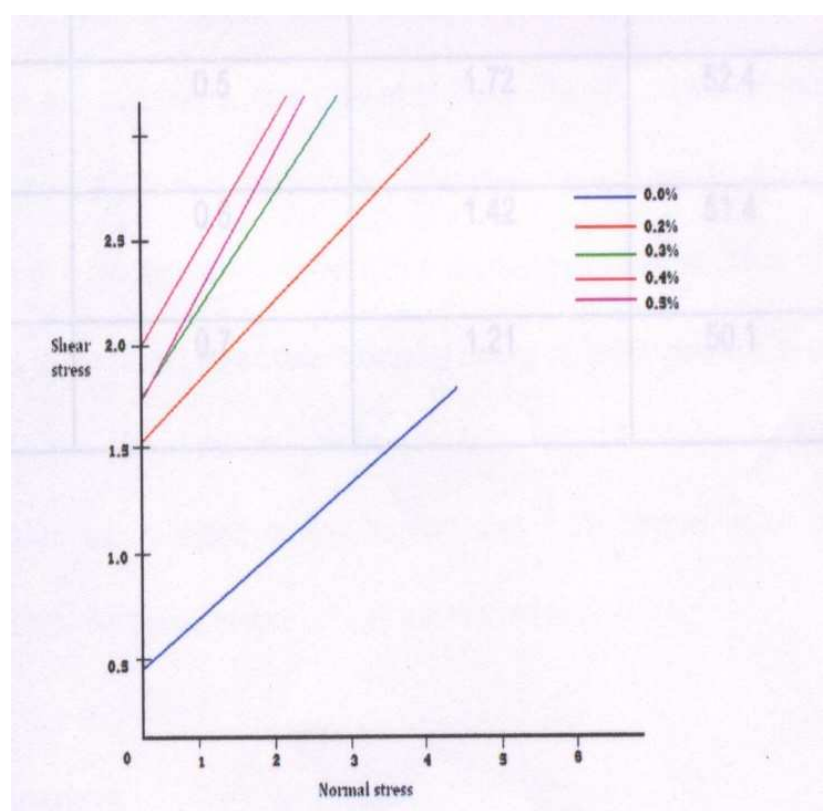

Figure 1: Normal stress and shear stress relationship.

Observation of the Table 3 and Figure1 indicates that with increase in normal stress, strength of reinforced soil increases. Also, these strengths increase with increase in fiber content up to $0.4 \%$ beyond which they decrease. The optimum fiber content is found to be $0.4 \%$.

\section{UNCONFINED COMPRESSIVE STRENGTH OF SOIL}

Unconfined compressive tests were performed on unreinforced and reinforced specimens for fiber content varying from 0 to $0.7 \%$.

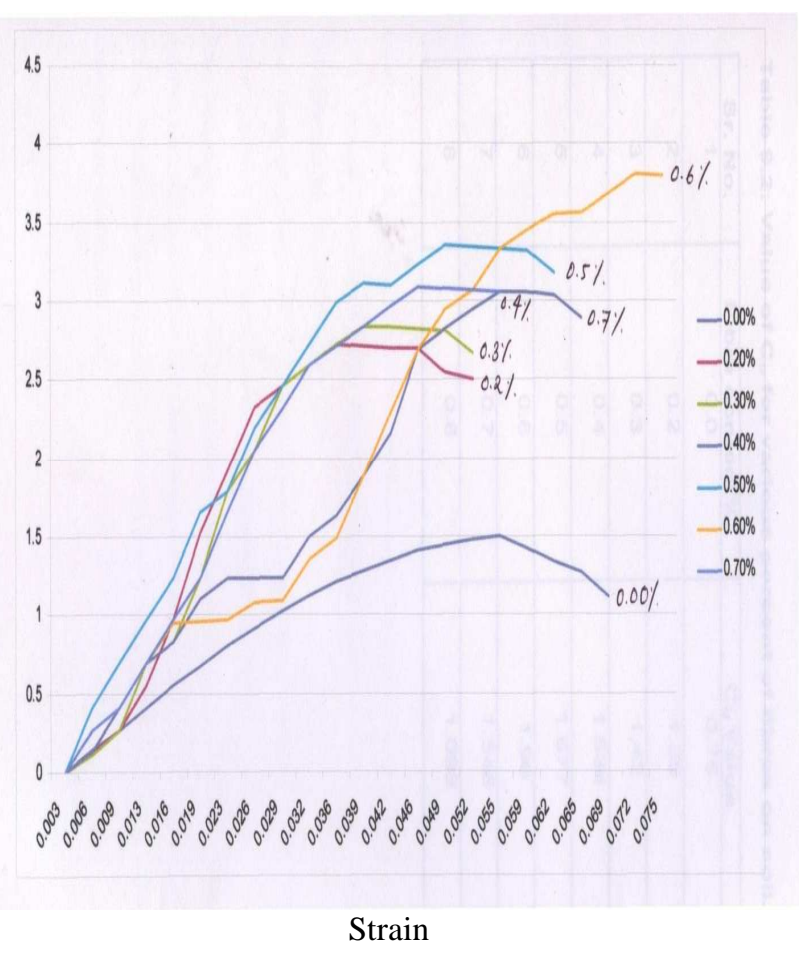

Figure 2: Stress and strain relationship.

Table 4: Shows the unconfined compressive strength of soil for different fiber contents

\begin{tabular}{|c|c|c|}
\hline S.No & $\begin{array}{c}\text { Fiber content } \\
(\%)\end{array}$ & $\begin{array}{c}\text { Unconfined compressive } \\
\text { Strength }\left(\mathrm{kg} / \mathrm{cm}^{2}\right)\end{array}$ \\
\hline .1. & 0.0 & 0.75 \\
\hline 2. & 0.2 & 1.35 \\
\hline 3. & 0.3 & 1.42 \\
\hline 4. & 0.4 & 1.53 \\
\hline 5. & 0.5 & 1.67 \\
\hline 6. & 0.6 & 1.90 \\
\hline 7. & 0.7 & 1.55 \\
\hline 8. & 0.8 & 1.09 \\
\hline
\end{tabular}

The results show that the reinforcement increases the strength. The maximum increase in stress, approximately 2.5 times higher than that for unreinforced soil, occurred for fiber content of $0.6 \%$. Also it can be seen from figure 2, that both failure stress and strain increase with increase in fiber content up to $0.6 \%$ beyond which both decrease. Thus, the optimum fiber content is to be $0.6 \%$. 


\section{CONCLUSIONS}

On the basis of experimental investigations the following conclusions are drawn

1. The optimum fiber content for achieving maximum CBR values of reinforced soil in un-soaked and soaked condition are $0.6 \%$ and $0.5 \%$ respectively.

2. The shear strength of soil increases with inclusion of fiber up to $0.4 \%$, beyond which it decreases.

3. Both cohesion and angle of friction increases with increase in fiber content up to $0.4 \%$, beyond which it remains almost constant.

4. The shear strength of fiber-reinforced soil occurs at higher strain compared to un- reinforced soil.

5. The rate of increase of peak shear strength increases with increases in fiber content commensurate with increase in normal stress.

6. The maximum increase in unconfined compressive strength is found to be 2.5 times higher than that for unreinforced soil at the optimum fiber content of $0.6 \%$. The corresponding failure strain is higher than that for un-reinforced soil.

\section{REFERENCES}

[1] Al WAhab ,R M and Al-Qurna, H.H,1995, "Fiber Reinforced Cohesive Soils for Application in Compacted Eart Structures", Proceedings of Geosynthetics 95, IFAI,Vol. 2, Nashville, Tennesse, USA, February 1995, pp. 433-446

[2] ASTM D 698, Standard test methods for Laboratory Compaction Characteristics of Soil using Standard effort $\left(600 \mathrm{kN} / \mathrm{m} / \mathrm{m}^{3)}\right.$, West Conshohocken, Pennsylvania, USA.

[3] Fletcher, C.S and Humphries, W.K, 1991, "California Bearing Ratio improvement of Remoulded soils by the addition of Polypropylene Fiber Reinforcement", Proceedings of Seventieth Annual Meeting, Transportation Research Board, Washington, DC, USA, pp. 80-86.

[4] Fretaig, D.R, 1986, "Soil Randomly Reinforced with Fibers", Journal of Geotechnical Engineering, ASCE, vol.112, No. 8, pp. 823-826.

[5] H. Jiang, Y.Cai and Liu, "Engineering Properties of soils reinforced by short discrete polypropylene fiber", Journal of Materials in civil Engineering, Vol. 22, 2010, pp. 1315-1322. 